\title{
Diet Quality and Growth Status of Children Aged Two to Six Years at Tuba Island, Langkawi, Malaysia
}

\author{
Nor Wasiqah Salleh", Syahrul Bariah Abdul Hamid ${ }^{1,2 *}$, Norazmir Md Nor ${ }^{1,2}$, Farhanah \\ Ahmad Shuhaimi ${ }^{1}$, Mazuin Kamarul Zaman ${ }^{1,2}$, Nazrul Hadi Ismail ${ }^{1}$ \\ ${ }^{1}$ Centre for Dietetics Studies, Faculty of Health Sciences, Universiti Teknologi MARA, Puncak Alam campus, \\ 42300 Puncak Alam, Selangor, Malaysia \\ ${ }^{2}$ Maternal, Infant and Young Child Nutrition (MiChild) Research Group, Faculty of Health Sciences, \\ Universiti Teknologi MARA, Puncak Alam campus, 42300 Puncak Alam, Selangor, Malaysia
}

\begin{abstract}
This study aimed to determine the prevalence of undernutrition, diet quality and its associated factors among children aged two to six years at Tuba Island. A total of 67 children paired with their mother or caregiver were participated in this study. A questionnaire containing socio-demographic characteristics, anthropometric measurements and two days of 24-hours dietary recall was administered. The Malaysian Healthy Eating Index (HEI) was used to assess the children's diet quality. The prevalence of underweight, stunting and wasting were $22.4 \%, 20.8 \%$ and $17.9 \%$, respectively. Mean total HEI score was $37.1 \pm 6.3$, which indicate poor diet. The children had low mean scores for vegetables, fruits, milk and dairy products as well as legumes. For socio-demographic factors, number of children per household was associated with diet quality. This study points out that overall low dietary score among these children and their diet quality had no association with their growth status. The low diet quality was prevalent; thus it did not contribute to differences in growth status among these children. Therefore, it is suggested further intervention should be taken to improve the nutrition quality of these children.
\end{abstract}

Keywords: child undernutrition, diet quality, growth status, healthy eating index

\section{INTRODUCTION}

According to World Health Organization (WHO), malnutrition refers to inadequacy, excesses, or imbalances in energy and nutrient intake (WHO 2021). Undernutrition can be categorized into three, namely underweight, stunting and wasting. According to the United Nation Children's Fund (UNICEF), undernutrition has been dubbed as the 'silent emergency'. It has posed a great health risk to women and children worldwide (UNICEF 2021). One out of four children under five years of age in developing countries is undernourished, irrespective of the worldwide decline in underweight prevalence from 1990 to 2010 (United Nation 2011). Malaysia is one of South-East Asia countries with an upper-middle income. However, childhood malnutrition persists in the country and has become a general concern in Malaysia, particularly in rural communities (Wong et al. 2014). In a nutrition survey at national level, the prevalence rates of stunting and thinness are $8.3 \%-8.8 \%$ and $5.2 \%-6 \%$ respectively among urban and rural children aged six months to 12 years (Poh et al. 2013). In addition, a study in a selected kindergarten from urban and rural areas in Selangor found that the rates of stunting and wasting in children from rural areas were higher with $28.6 \%$ and $31 \%$ compared to children living in an urban region with $15 \%$ and $22 \%$ respectively (Aziz \& Devi 2012). Same findings were found among indigenous population across states in Malaysia ranging from $35 \%$ to $76 \%$ of indigenous children under five years old were suffering from undernutrition, where stunting was more prevalent than underweight (Chua et al. 2012; Geik et al. 2016; Murtaza et al. 2018; Yen et al. 2018).

An individual's dietary intake determines the quality of a diet; thus, it is important to adequately consume food with high quality and quantity of various nutrients in order for the body to sufficiently absorb macronutrients and

\footnotetext{
"Corresponding Author: tel: +60132884252, email: syahrulbariah@uitm.edu.my

(Received 02-07-2021; Accepted 22-10-2021; Published 29-11-2021)
} 
micronutrients (Ihab 2015). Adequate intake during the first two years of life plays a vital role for the nutritional status of children in the future, as it can become a risk factor for stunting (UNICEF 2013). Individual, particularly children suffering from undernutrition may susceptible to illness, delayed mental and motor development as well as other health risks that may take a toll on their health and resulting in adverse effect beyond their childhood (WHO 2019). Good quality diet may represent adequate nutrient intake that children need to improve their growth and development in physical, cognitive and psychosocial terms (Cheng \& Buyken 2013). In rural areas, malnourished children are vulnerable to insufficient food intakes, which will lead to macronutrient and micronutrient deficiencies. This deficiency reflects their poor diet quality (Cheng \& Buyken 2013). Malaysian Healthy Eating Index (MHEI) has become one of the recognizable tools to assess diet quality in Malaysia reflecting the local context, thus was used in this study.

Tuba Island is situated in Langkawi and it is smaller than the main island thus having smaller geographical areas. Tuba Island is considered a rural area as it is still constrained by remoteness and under-development and limited livelihood opportunities, therefore it was chosen as the study location. According to previous research, geographical differences affect the access of food which are linked to economic barriers to acquiring healthy food options (Vilar-Compte et al. 2014). To date, communities living on the island still maintain traditional occupation and culture. The village in Tuba Island was known as a traditional fishing village since their main source of income was from working as fishermen, which may contribute to their low socio-economic status. Thus, the objectives of this study were: (1) to determine the prevalence of undernutrition among children aged two to six years; (2) to assess diet quality status among children and its association with socio-demographic variables and (3) to investigate the association between diet quality and growth status of children in Tuba Island.

\section{METHODS}

\section{Design, location, and time}

A cross-sectional study was conducted in Tuba Island, Langkawi, located off the main island. It is situated five kilometers southwest of
Kuah Jetty, Langkawi. This study was conducted for two weeks in August 2020.

\section{Sampling}

The convenience sampling method was used to search for potential subjects. The respondents were approached by researchers by visiting from home to home during data collection. According to the local authority, the number of children and women within the inclusion criteria was limited and therefore, convenience sampling was used. The sample size for this study was calculated using the formula developed by Cochran (Cochran 1963). The estimated proportion is 0.807 based on the prevalence of poor diet quality in Kuala Lumpur (Rezali et al. 2015) which is $80.7 \%$ desired confidence level of $95 \%$ and desired precision of 0.1 . Therefore, the required sample size was 59 . The prevalence of poor diet quality from Kuala Lumpur is chosen as it has higher prevalence compared to other study.

Attrition rate of $20 \%$ was used to increase the number of respondents participated in this study, therefore, the final total sample size obtained was $(n=71)$. Children aged two to six years were paired with their mother or caregiver. In a household where a mother had more than one child age between two and six years, the youngest one was selected. In this study, children were excluded if they had physical impairment, intellectual development delays, and chronic disease that can affect child's growth includes congenital and acquired diseases. Intellectual developmental delays were observed by the researchers through the children's ability to know full name, gender and understand basic instructions.

\section{Data collection}

The data was collected in the participants' house and performed in August 2020. A total of 67 children and care givers dyads were qualified to participate after screening for inclusion and exclusion criteria. Ten children were ineligible to join the study since their age did not meet the requirement. Before data collection process, the research protocol was explained to the caregivers of these children. If they agreed to participate, verbal and written informed consent were signed. Safety measures during Covid-19 pandemic were implemented, where researcher was obligated to wear face masks and gloves as well as 
sanitized before and after data collection process. Respondents also were sanitized and their body temperature were checked. Social distancing (one meter) was applied during interview and anthropometric measurements. The session was limited to only 15 to 20 minutes. The application of ethical review was submitted and approved by Research Ethics Committee (REC) Universiti Teknologi MARA(UiTM) with reference number REC/05/2021 (UG/MR/421).

Household demographic and socioeconomic status. A face-to-face interview was conducted with the caregiver using a structured questionnaire. The questionnaire consists of 11 items, including the age of mother, marital status, educational level of father and mother, household income, number of persons contribute to household income, household size category, employment status of father and mother, number of children per household and household food expenditure

Anthropometric measurements. The subject's weight was measured using SECAdigital weighing scales (to the nearest $0.1 \mathrm{~kg}$ ) while the height was measured using non-stretchable measuring tape. In order to increase the accuracy of the height measurement, the subjects were told to remove shoes, hats and any other head wears and feet need to be flat on the floor while standing straight with the back against the wall. The date of birth of subjects were obtained from their birth certificates. The age, weight and height of the children were translated into three indices; weight-for-age, height-for-age and weight-forheight, where the z scores were obtained based on the WHO Child Growth Standard median. Underweight was defined as weight-for-age less than -2 SD, stunting was defined as height-forage less than -2 SD and similarly, wasting was defined as weight-for-height less than $<-2 \mathrm{SD}$.

Dietary intake assessment. Dietary intake of the children was obtained by interviewing the mother or the caregiver using the 24-hours diet recall on one day from weekday and one on weekend. The mothers were asked to remember the foods and beverages consumed by their children in the last 24-hours with the estimation of serving sizes using household measures such as teaspoons, tablespoons, cups, glass, bowls, saucer, etc. along with the Food Atlas: Size Portion and Exchange to achieve a more reliable estimate of portion sizes (Suzana et al. 2015). The data obtained were analyzed using Nutritionist Pro Software and compared to the Recommended Nutrient Intake (RNI) for Malaysia (NCFFN 2017). Malaysian Healthy Eating Index (MHEI). Malaysian Healthy Eating Index was developed by Lee et al. (2011) and was used to assess the diet quality of an individual (Lee et al. 2011). MHEI consist of seven components of food groups (grains and cereals, vegetables, fruit, meat, poultry and eggs, fish and seafood, legumes, milk and milk products) and two components of nutrients (percentage of energy intake from fat and sodium), with a total of nine components. The calculation scoring component was based on the recommended serving size in the Malaysian Dietary Guidelines for Children and Adolescent (MDG) (Majlis Keselamatan Makanan dan Pemakanan Kebangsaan \& Malaysia 2013). The score for each HEI component is computed using the formula:

$$
\frac{\text { actual serving consumed based on respondent's diet recall }}{\text { recommended serving size based on } M D G} \times 10
$$

Formulas for composite score:

$$
\frac{\text { total score obtained from } 9 \text { components }}{\text { maximum score of } 90} \times 100 \%
$$

The total HEI score will be obtained by summing up the scores for each element. A composite score above $80 \%$ indicated a good diet, a score between $51 \%$ to $80 \%$ indicated needs of improvement and a score of less than $51 \%$ indicated poor diet (Pei et al. 2018).

\section{Data analysis}

The data collected was analyzed using Statistical Package for Social Sciences (SPSS) version 25.0. Descriptive statistics were reported as mean \pm standard deviation, frequencies and percentages. Data for anthropometric measurements were analyzed using WHO AnthroPlus. To generate value for weight-for-age $z$ scores (WAZ), height-for-age z scores (HAZ) and weight-for-height $\mathrm{z}$ scores (BAZ), the birth date, height and weight measurements of the children were inserted into the software. The association between socio-demographic variables with diet quality were determined by Fisher Exact test. In contrast, the Pearson Correlation test was used to determine the correlation between the children's HEI score and growth status, the children's HEI score and growth status. P-value of less than 0.05 was considered statistically significant. 


\section{RESULTS AND DISCUSSION}

Table 1 shows the socio-demographic characteristics of 67 household participated in the study. Most of the parents, father and mother had secondary level education with the proportion of $62.7 \%$ and $73.1 \%$ respectively. For monthly household income, nearly one third (29.9\%) of the family has an income less than RM908 (USD218) or considered as below the poverty line. As for the parents' employment status, most fathers were self-employed with a proportion of $58.2 \%$, who mostly worked as fishermen, while most mothers were housewives, $74.6 \%$.

Table 1. Socio-demographic characteristics of respondent

\begin{tabular}{|c|c|c|c|}
\hline Respondent characteristics & Number $(n=67)$ & Percentage (\%) & Mean \pm SD \\
\hline Age of mother (year) & & & $34.9 \pm 6.8$ \\
\hline \multicolumn{4}{|l|}{ Marital status } \\
\hline Married & 62 & 92.5 & \\
\hline Widowed/divorced & 5 & 7.5 & \\
\hline \multicolumn{4}{|l|}{ Education level of father } \\
\hline Primary education & 20 & 29.9 & \\
\hline Secondary education & 42 & 62.7 & \\
\hline Tertiary education & 2 & 3.0 & \\
\hline \multicolumn{4}{|l|}{ Education level of mother } \\
\hline Primary education & 16 & 23.9 & \\
\hline Secondary education & 49 & 73.1 & \\
\hline Tertiary education & 2 & 3.0 & \\
\hline \multicolumn{4}{|l|}{ Household income (RM) } \\
\hline$\leq$ RM908 (USD218) & 20 & 29.9 & \\
\hline RM909-RM2,208 (USD219-USD532) & 42 & 62.7 & \\
\hline$\geq \mathrm{RM} 2,209$ (USD532) & 5 & 7.5 & \\
\hline \multicolumn{4}{|l|}{ Number of persons contribute to household income } \\
\hline None & 3 & 4.5 & \\
\hline Only & 48 & 71.6 & \\
\hline More than one & 16 & 23.9 & \\
\hline \multicolumn{4}{|l|}{ Household size category } \\
\hline$\leq 5$ members & 34 & 50.7 & \\
\hline 6-8 members & 29 & 43.3 & \\
\hline$\geq 9$ members & 4 & 6.0 & \\
\hline \multicolumn{4}{|l|}{ Employment status of father } \\
\hline Government/private sector & 25 & 37.3 & \\
\hline Self-employed & 39 & 58.2 & \\
\hline \multicolumn{4}{|l|}{ Employment status of mother } \\
\hline Government/private sector & 8 & 11.9 & \\
\hline Self-employed & 9 & 13.4 & \\
\hline Housewife & 50 & 74.6 & \\
\hline \multicolumn{4}{|l|}{ Number of children per household } \\
\hline$\leq 3$ children & 43 & 64.2 & \\
\hline 4-6 children & 23 & 34.3 & \\
\hline$\geq 6$ children & 1 & 1.5 & \\
\hline \multicolumn{4}{|l|}{ Household food expenditure (RM) } \\
\hline$\leq \mathrm{RM} 500(\leq \mathrm{USD} 120)$ & 37 & 55.2 & \\
\hline RM501-RM749.99 (USD120-USD180) & 22 & 32.8 & \\
\hline$\geq \mathrm{RM} 750(\geq \mathrm{USD} 180)$ & 8 & 11.9 & \\
\hline
\end{tabular}

RM: Ringgit Malaysia; USD: United States Dollar 
Of the 67 children participated in this study, $55.2 \%$ were male and $44.8 \%$ were female. In this study, more than half of the children had normal growth. Twenty-two point four percent were underweight, $20.8 \%$ were stunted and $17.9 \%$ were wasted (Table 2).
Table 3 displays the average score of each component and total HEI score. The mean HEI score was $37.1 \pm 6.3$ which indicates that children in Tuba Island were overall had poor diet quality. The low mean scores for the components of the seven food groups, were specifically for

Table 2. Anthropometric characteristic of children

\begin{tabular}{lccc}
\hline \multicolumn{1}{c}{ Variables } & Frequency $(\mathrm{n}=67)$ & Percentage (\%) & Mean \pm SD \\
\hline Weight (kg) & & & $15.5 \pm 4.1$ \\
Height (cm) & & & $101.2 \pm 13.5$ \\
Age (months) & 20 & 29.9 & $52.2 \pm 17.7$ \\
$24-36$ & 47 & 70.2 & \\
$37-72$ & & & \\
Gender & 37 & 55.2 & \\
$\quad$ Male & 30 & 44.8 & $-0.9 \pm 1.6$ \\
Female & & & \\
Weight-for-age (WAZ) & 4 & 6.0 & \\
$\quad$ Severe underweight & 11 & 16.4 & \\
Moderate underweight & 49 & 73.1 & \\
$\quad$ Normal & 3 & 4.5 & \\
$\quad$ Overweight & & & \\
Height-for-age (HAZ) & 7 & 10.4 & $-0.8 \pm 1.9$ \\
Severe stunting & 7 & 10.4 & \\
Moderate stunting & 52 & 77.6 & \\
Normal & 1 & 1.5 & $-0.5 \pm 2.0$ \\
$\quad$ High & & & \\
Weight-for-height (BAZ) & 4 & 6.0 & \\
Severe wasting & 8 & 11.9 & \\
Moderate wasting & 41 & 61.2 & \\
Normal & 9 & 13.4 & \\
Possible risk of overweight & 1 & 1.5 & \\
Overweight & 4 & 6.0 & \\
Obese & & & \\
\hline
\end{tabular}

Table 3. The average score of each component and total HEI score

\begin{tabular}{lcccc}
\hline HEI components & $\begin{array}{c}\text { Score } \\
\text { range }\end{array}$ & $\begin{array}{c}\text { Criteria for minimum } \\
\text { score 0 (serving/day) }\end{array}$ & $\begin{array}{c}\text { Criteria for maximum } \\
\text { score 10 (serving/day) }\end{array}$ & $\begin{array}{c}\text { Average score } \\
\text { (Mean } \pm \text { SD) }\end{array}$ \\
\hline Food groups & & & & \\
$\quad$ Grains and cereals & $0-10$ & 0 & $2-3$ & $8.1 \pm 1.8$ \\
Vegetables & $0-10$ & 0 & 2 & $1.8 \pm 1.8$ \\
Fruits & $0-10$ & 0 & 2 & $0.6 \pm 1.1$ \\
Meat, poultry and eggs & $0-10$ & 0 & $1 / 2$ & $7.5 \pm 2.7$ \\
Fish and seafood & $0-10$ & 0 & $1 / 2-1$ & $6.6 \pm 2.9$ \\
Legumes & $0-10$ & 0 & $1 / 2$ & $0.0 \pm 0.0$ \\
Milk and dairy products & $0-10$ & 0 & 2 & $3.0 \pm 2.3$ \\
Nutrients & & & & \\
Total fat & $0-10$ & $\geq 30 \%$ energy from fat & $\leq 25 \%$ energy from fat & $1.0 \pm 2.5$ \\
$\quad$ Sodium & $0-10$ & $\geq 1,900 \mathrm{mg}$ & $\leq 1,200 \mathrm{mg}$ & $1.0 \pm 2.5$ \\
Total HEI score & $0-100$ & - & - & $37.1 \pm 6.3$ \\
\hline
\end{tabular}

HEI: Healthy Eating Index 
vegetables (1.8), fruits (0.6), milk and milk products (3.0) and legumes (0.0). This suggests a low level of intake of these food groups as opposed to the dietary guidelines. However, the subjects obtained high scores of $8.1 \pm 1.8,7.5 \pm 2.7$ and $6.6 \pm 2.9$ for grains and cereals, meat, poultry, eggs, fish, and seafood components. The children obtained low mean scores for percentages of energy from fat with $1.0 \pm 2.5$ for nutrient components.

Fisher Exact Test result indicates an association between diet quality status and the number of children per household $(\mathrm{p}=0.044)$. Families with less than three children in a household had higher percentages of children with poor diet $(63.5 \%)$ than families with more than three children (Table 4).

Table 5 shows the correlation between HEI score and growth status indices which is weightfor-age (WAZ), height-for-age (HAZ) and weight-for-height (BAZ). The results revealed that there was a non-significant relationship in those three growth status indices of WAZ, HAZ and BAZ with HEI score. Thus, this finding

Table 4. Socio-demographic characteristics by diet quality status of the children aged two to six years

\begin{tabular}{|c|c|c|c|}
\hline \multirow{2}{*}{ Variables } & Need improvement $(\mathrm{n}=4)$ & Poor $(n=63)$ & \multirow{2}{*}{$\mathrm{p}$} \\
\hline & $\mathrm{n}(\%)$ & $\mathrm{n}(\%)$ & \\
\hline The educational level of the father & & & 0.546 \\
\hline Primary & $0(0.0)$ & 21(31.7) & \\
\hline Secondary/tertiary & $3(75.0)$ & $41(65.1)$ & \\
\hline The educational level of the mother & & & 1.000 \\
\hline Primary & $1(25.0)$ & $15(23.8)$ & \\
\hline Secondary/tertiary & $3(75.0)$ & $48(.76 .2)$ & \\
\hline Household income (RM) & & & 1.000 \\
\hline$<$ RM98 $(<$ USD218) & $1(25.0)$ & $19(30.2)$ & \\
\hline RM909-RM2,208 (USD219-USD532) & $3(75.0)$ & $39(61.9)$ & \\
\hline$>\mathrm{RM} 2,209(>\mathrm{USD} 532)$ & $0(0.0)$ & $5(7.9)$ & \\
\hline No. of persons contribute to household income & & & 1.000 \\
\hline None & $0(0.0)$ & $4(6.3)$ & \\
\hline Only & $3(75.0)$ & $44(69.8)$ & \\
\hline More than one & $1(25.0)$ & $15(23.8)$ & \\
\hline Household size category & & & 0.157 \\
\hline$\leq 5$ members & $4(100.0)$ & $30(47.6)$ & \\
\hline 6-8 members & $0(0.0)$ & $29(46.0)$ & \\
\hline$\geq 9$ members & $0(0.0)$ & $4(6.3)$ & \\
\hline Employment status of the father & & & 0.055 \\
\hline Government/private sector & $3(75.0)$ & $22(34.9)$ & \\
\hline Self-employed & $0(0.0)$ & $39(61.9)$ & \\
\hline Employment status of the mother & $0(0.0)$ & $8(12.7)$ & \\
\hline Government/private sector & & & 0.700 \\
\hline Self-employed & $1(25.0)$ & $8(12.7)$ & \\
\hline Housewife & $3(75.0)$ & 47 (74.6) & \\
\hline Number of children per household & & & 0.044 \\
\hline$\leq 3$ children & $3(75.0)$ & $40(63.5)$ & \\
\hline $4--6$ children & $1(25.0)$ & $23(36.5)$ & \\
\hline Household food expenditure (RM) & & & 0.063 \\
\hline$\leq$ RM500 $(\leq \mathrm{USD} 120)$ & $2(50.0)$ & $35(55.6)$ & \\
\hline RM501-RM749.99 (USD120-USD180) & $2(50.0)$ & $22(34.9)$ & \\
\hline$\geq$ RM750 ( $\geq$ USD180) & $0(0.0)$ & $6(9.5)$ & \\
\hline
\end{tabular}

Fisher's exact test was used since cells have an expected count of less than 5; RM: Ringgit Malaysia; USD: United States Dollar. 


\section{Diet quality and growth status of children at Tuba Island, Malaysia}

Table 5. Correlation between HEI score and growth status

\begin{tabular}{lcc}
\hline \multicolumn{1}{c}{ Variables } & HEI score & $\mathrm{p}$ \\
& $\mathrm{r}$ & \\
\hline Weight-for-age (WAZ) & -0.035 & 0.778 \\
Height-for-age (HAZ) & -0.008 & 0.947 \\
Weight-for-height (BAZ) & -0.072 & 0.562 \\
\hline $\begin{array}{l}\text { Correlation is significant at the } 0.05 \text { level (2-tailed) } \\
\text { HEI: Healthy Eating Index }\end{array}$
\end{tabular}

suggested that their diet quality cannot indicate the growth status of the children due to the large majority had poor diet.

This study examined the prevalence of undernutrition of children in Tuba Island, Langkawi. The overall prevalence of undernutrition in this study are $22.4 \%, 20.8 \%$ and $17.9 \%$ respectively for underweight, stunting and wasting. In Indonesia, the percentage of stunting, underweight and wasting were higher in rural compared to urban areas with $39.2 \%$, $28.9 \%$ and $6.0 \%$ respectively which is slightly higher than findings in this study (Sandjaja et al. 2013). In another study in Philippines, the rate of underweight, stunting and wasting was $26.4 \%, 37.7 \%$ and $11.2 \%$, which is slightly higher than this study findings. Children in a Household Headed by Fisherfolks (HHF) had the highest prevalence of undernutrition among other occupational groups, including households headed by forestry and related workers, compared to other occupational groups (Capanzana et al. 2018). Tuba Island is considered a rural region due to its low population density and traditional fishing villages. Thus, as most of the children living in Tuba Island come from families of fishermen, the result was consistent with this study. In comparison with a study in other rural area in Malaysia, the prevalence of wasting and stunting among children in fishermen community in Terengganu were $36.6 \%$ and $6.7 \%$ respectively (Bahtiar et al. 2021).

A healthy and balanced diet is crucial for children's development and growth. Despite the importance of having a good diet quality, most of the children living in Tuba Island had poor diet quality. Most children did not comply with the recommended intake of fruits, vegetables, milk and dairy products and legumes, as shown by the low average score for these components.
However, most of the children exceeded both the recommended sodium intake and the percentage of energy intake from fat. This result partially aligns with those of Koo et al. (2016) who reported that the dietary intake of Malaysian children for six food groups, including cereals/ grains, fruits, vegetables, legumes, fish and dairy products, was below the recommended levels in the Malaysian Dietary Guidelines (MDG) (Koo et al. 2016). The low consumption of dairy products among the subjects may be due to the low availability of these food groups in lowincome households. Khor et al. (2015) stated that the consumption of milk by low-income children was significantly lower than that of households with high incomes (Khor et al. 2015). Low scores for fruits, vegetables and legumes may be due to the children's low preferences and exposure towards these food groups.

For nutrient components, they obtained both low and moderate scores for fat and sodium. Low mean scores for fat indicate that the children's fat intake was high. Based on the dietary data collected, most of the children eat fried and high-fat foods during their main meal, such as fried chicken, fried fish, fried rice, fried noodles, French fries, nasi lemak, roti canai, and burger. Fast foods such as French fries and burger have poor nutritional quality and the consumption of these foods may lead to higher calorie intake and poor diet quality among children (Nemati et al. 2020). In addition, fish crackers, soy sauce, chicken or beef patty and instant noodles are common high sodium foods consumed by the children. High intake of these nutrients will bring adverse effects to health if not controlled.

This study analyzed socio-demographic characteristics and its association with diet quality. Only one socio-demographic variable was associated with diet quality, which is the number of children per household. The size of the family including number of children in a family determines their nutritional consumption in such a way that the allocation of food per child is likely to decrease with the increase in the number of children, which, in turn, may adversely affect the nutritional status of children (Bhattacherjee et al. 2016). However, this study found that more children from household with less than three children had poor diet. In this study this can also partly be explained by the diminishing effect of income on diet quality, this may be due to rural 
families with more income leads to increase number of children. While on the other hand, poor family had less children. In contrast with a finding from Appelhans et al. (2012), they found a positive association on household income and diet quality where households with lower income reported purchasing fewer fiber, fruits and vegetables but more sugary foods, in comparison with households with higher income (Appelhans et al. 2012).

This study found that there was no significant association found between diet quality and growth status. The findings were in contrast with a study conducted in rural Bangladesh, where the prevalence of children who are stunted is high, and the overall diet quality is likely to be low (Rah et al. 2010). Due to short periods of study, a regular eating pattern and usual food intake by the children cannot be obtained, which may be a possible reason for lack of association for these variables. Thus, it cannot be proven that the children's dietary intake will affect their growth since there may be other potential factors that may interfere with the children's growth.

A few limitations worth to be noted in this research. The use of statistical analysis and reflective of the general population at risk is constrained by the small sample size and convenience sampling method. The children's diet recall was obtained from the mothers, which may interfere with the accuracy of the data because the data recall relies on the respondent's memory. This can result in under-reporting or over-reporting of the children's food intake.

\section{CONCLUSION}

This research provides baseline information on the diet quality and children's growth status in Tuba Island, Langkawi. The overall low HEI score was found which indicates poor diet was prevalent in the study area. Their intake was largely made up of highly energydense foods with poor nutritional values. Number of children per household was associated with diet quality where family with less children had poorer diet quality. No significant association was found between diet quality and growth status. It is recommended that further research need to be carried out to determine the relationship between diet quality of these children with their growth status. Findings of this study may also benefit relevant agencies to implement education program in order to provide the right knowledge on nutrition and health for this targeted population to tackle their poor dietary habits and improve their overall well-being.

\section{ACKNOWLEDGEMENT}

We would like to thank all participants who took part in this study and the authority of Tuba Island, Langkawi, for their support. This work was fully supported by the Lestari SDG grant (600-RMC/LESTARI SDG-T5/3 180/2019). This manuscript is written based on a thesis entitled 'Diet Quality and Growth Status of Children at Pulau Tuba, Langkawi' and is not published elsewhere.

\section{DECLARATION OF INTERESTS}

The authors have no conflict of interest.

\section{REFERENCES}

Appelhans BM, Milliron BJ, Woolf K, Johnson TJ, Pagoto SL, Schneider KL, Whited MC, Ventrelle JC. 2012. Socioeconomic status, energy cost, and nutrient content of supermarket food purchases. Am J Prev Med 42(4):398-402. https://doi. org/10.1016/j.amepre.2011.12.007

Aziz MFA, Devi MN. 2012. Nutritional status and eating practices among children aged 4-6 years old in selected urban and rural kindergarten in Selangor, Malaysia. Asian J Clin Nutr 4(4):116-131. https://doi. org/10.3923/ajen.2012.116.131

Bahtiar BA, Ali A, Yusof HM, Kamarudin KS. 2021. Child development and nutritional status of children under five: A crosssectional study of a fishermen community in Terengganu, Malaysia. J Gizi Pangan 16(2):91-100. https://doi.org/10.25182/ jgp.2021.16.2.91-100

Bhattacherjee S, Datta S, Ray K, Mukhopadhyay DK. 2016. Nutrient adequacy and its correlation in a sub-Himalayan region of West Bengal, India. J Family Med Prim Care 5(2):314. https://doi. org/10.4103/2249-4863.192315

Capanzana M, Aguila D, Gironella G, Montecillo K. 2018. Nutritional status of children 
ages $0-5$ and $5-10$ years old in households headed by fisherfolks in the Philippines. Archives of Public Health 76(1)-8. https:// doi.org/10.1186/s13690-018-0267-3

Cheng G, Buyken A. 2013. Diet Quality in Childhood: Impact on Growth. (eds) Diet Quality. New York (NY): Humana Press.

Chua EY, Zalilah MS, Chin YS, Norhasmah S. 2012. Dietary diversity is associated with nutritional status of Orang Asli children in Krau Wildlife Reserve, Pahang. Malays J Nutr 18:1-13

Cochran WG. 1963. Sampling Techniques. 2nd Ed. New York (NY): John Wiley and Sons Inc.

Geik OP, Sedek R, Awang AF. 2016. Malnutrition and associated factors of aboriginal preschoolers in Gua Musang, Kelantan, Malaysia. Pak J Nutr 15(2):133-139. https://doi.org/10.3923/pjn.2016.133.139

Ihab AN, Rohana AJI, Wan Manan WM, Wan Suriati WN, Zalilah MS, Mohamed Rusli A. 2015. Assessment of food insecurity and nutritional outcomes in Bachok, Kelantan. J Nutr Food Sci 5(3). https://doi. org/10.4172/2155-9600.1000373

Khor GL, Shariff ZM, Sarima S, Huang SLM, Mohamad M, Chan YM, Chin YS, Yusof BNM. 2015. Milk drinking patterns among Malaysian urban children of different household income status. J Nutr Health Sci 2(1):105. https://doi.org/10.15744/23939060.1.401

Koo H, Poh B, Lee S, Chong K, Bragt M, Abd Talib R. 2016. Are Malaysian children achieving dietary guideline recommendations? Asia Pac J Public Health 28(5_suppl):8S-20S. https://doi. org/10.1177/ $\overline{10} 10539516641504$

Lee TT, Norimah AK, Safiah MY. 2011. Development of Healthy Eating Index for Malaysian adults. Proceedings of 26th Scientific Conference of the Nutrition Society of Malaysia, p. 101-102, March 24-25, Kuala Lumpur, Malaysia. Selangor $(\mathrm{KL})$ : Nutrition Society of Malaysia.

Majlis Keselamatan Makanan dan Pemakanan Kebangsaan \& Malaysia. Kementerian Kesihatan. 2013. Malaysian Dietary Guidelines for Children and Adolescents. Technical Working Group on Nutritional Guidelines. Malaysia (KL): National
Coordinating Committee on Food and Nutrition

Murtaza SF, Gan WY, Sulaiman N, Shariff ZM. 2018. Factors associated with stunting among Orang Asli preschool children in Negeri Sembilan, Malaysia. Malays J Nutr 24(2):215-226

[NCFFN] National Coordinating Committee on Food and Nutrition, Ministry of Health Malaysia. 2017. Recommended Nutrient Intakes for Malaysia. Putrajaya (KL): Select Kami Resources.

Nemati A, Matin S, Sadegh-Hoseini M, AlipanahMoghadam R, Mohajeri M. 2020. Is there any difference in fast food consumption between children with different obesity status in Ardabil-Iran? Obes Med 20:100293. https://doi.org/10.1016/j. obmed.2020.100293

Pei C, Appannah G, Sulaiman N. 2018. Household food insecurity, diet quality, and weight status among indigenous women (Mah Meri) in Peninsular Malaysia. Nutr Res Pract 12(2):135. https://doi.org/10.4162/ nrp.2018.12.2.135

Poh BK, Ng BK, Haslida MDS, Nik Shanita S, Wong JE, Budin SB, Ruzita AT, Ng LO, Khouw I, Norimah AK. 2013. Nutritional status and dietary intakes of children aged 6 months to 12 years: Findings of the nutrition survey of Malaysian children (SEANUTS Malaysia). $\mathrm{Br} \mathrm{J}$ Nutr 2013(110):S21-S35. https://doi. org/10.1017/S0007114513002092

Rah JH, Akhter N, Semba RD, Pee SD, Bloem MW, Campbell AA, Moench-Pfanner, R, Sun K, Badham J, Kraemer K. 2010. Low dietary diversity is a predictor of child stunting in rural Bangladesh. Eur $\mathrm{J}$ Clin Nutr 64(12):1393-1398. https://doi. org/10.1038/ejen.2010.171

Rezali FW, Chin YS, Mohd ShariffZ, Yusof BNM, Sanker K, Woon FC. 2015. Evaluation of diet quality and its associated factors among adolescents in Kuala Lumpur, Malaysia. Nutr Res Pract 9(5):511. https:// doi.org/10.4162/nrp.2015.9.5.511

Sandjaja S, Budiman B, Harahap H, Ernawati F, Soekatri M, Widodo Y, Sumedi E, Rustan E, Sofia G, Syarief SN, Khouw I. 2013. Food consumption and nutritional and biochemical status of 0.5-12-year- 
old Indonesian children: The SEANUTS study. British Journal of Nutrition 110(S3), S11-S20. https://doi.org/10.1017/ S0007114513002109

Suzana S, Noor Aini MY, Nik Shanita S, Zahara AM, Hasnah H. 2015. Atlas of Food Exchanges and Portion Sizes, 3nd ed. Kuala Lumpur (KL): MDC Publishers Sdn. Bhd.

[UNICEF] United Nations Children's Fund. 2013. Improving Child Nutrition. The Achievable Imperative for Global Progress. New York (USA): UNICEF.

[UNICEF] United Nations Children's Fund. 2021. The State of the world's Children. https://www.unicef.org/reports/state-ofworlds-children-2021 [Accessed 19 June 2021].

United Nations. 2011. The Millennium Development Goals Report 2011. New York (USA): United Nations.
Vilar-Compte M, Bernal-Stuart A, SandovalOlascoaga S, Pérez-Lizaur AB. 2014. The effect of Mexican household food security status and income distribution on food access. Food Stud Interdiscip J 3(2):31-40. https://doi.org/10.18848/2160-1933/CGP/ v03i02/40570

[WHO] World Health Organization. 2021. Fact Sheets - Malnutrition. https://www.who.int/ news-room/fact-sheets/detail/malnutrition [Accessed 19 June 2021].

Wong H, Moy FM, Nair S. 2014. Risk factors of malnutrition among preschool children in Terengganu, Malaysia: A case control study. BMC Public Health 14(1). https:// doi.org/10.1186/1471-2458-14-785

Yen WC, Shariff ZM, Adznam SNA, Sulaiman N, Chin YS. 2018 Weight and height faltering in the indigenous children (Orang Asli) of peninsular Malaysia during the first 2 years of life. Asia Pac J Clin Nutr 27(4):886-92 